\title{
Creche e família ou creche e famílias: o contexto dessa relação na contemporaneidade
}

\author{
Letícia Veiga Casanova*
}

\begin{abstract}
Resumo
O mundo pós-moderno é marcado por uma multiplicidade de identidades, formadas e transformadas continuamente pelos sistemas culturais que as rodeiam. A creche, assim, não atua exclusivamente com um tipo de família, mas está constantemente relacionando-se com os sentidos plurais das famílias. Dessa forma, este artigo objetiva discutir a relação entre creche e famílias no contexto da contemporaneidade e, para tanto, utiliza-se da pesquisa bibliográfica. Autores como Lahire (1995, 2002, 2006), nos ajudam a pensar sobre essa relação e reconhece as experiências socializadoras heterogêneas das famílias e a perspectiva de que é impossível agir como se estivéssemos ligados e a um espaço cultural homogêneo. Hall (2014) e Lyotard (2013) conceituam a pósmodernidade e caracterizam os sujeitos da contemporaneidade. As conclusões desse estudo apontam para a importância de se entender as famílias no plural, reconhecendo suas especificidades e planejando ações que ultrapassem a visão da família nuclear moderna.
\end{abstract}

Palavras-chave: Creche. Infância. Famílias. Contemporaneidade.

\section{Nursery and family or nursery and families: the context of this relationship in contemporaneity}

\begin{abstract}
The postmodern world is marked by a multiplicity of identities, formed and continually transformed by the cultural systems that surround them. Thus, this paper aims to discuss the relationship between nursery and families in the contemporary context and highlight the need to understand families in their plurality. Drawing from Lahire (1995, 2002, 2004, 2006), this paper highlights the importance of understanding the families in the plural form, recognizing their specificities and planning actions that exceed the vision of the modern nuclear family. Hall (2014) and Lyotard (2013) conceptualize post-modernity and characterize the subject of contemporaneity. Nurseries do not operate exclusively with one type of family, but it is constantly relating with the plural meanings of families.
\end{abstract}

Keywords: Nursery. Childhood. Families. Contemporaneity.

\section{Introdução}

De segunda a sexta-feira, geralmente a partir das 7 horas, os portões das creches já estão abertos para receber pais, mães, irmãos, avós que trazem suas crianças, deixando-as com os profissionais e seguindo caminho ao trabalho ou aos seus afazeres diários. É possível perceber que alguns demoram-se mais nas despedidas feitas na porta da sala e fazem questão de informar à professora sobre como sua criança passou a noite ou contam alguma situação acontecida em casa. Outros se limitam ao bom dia e entregam seu filho e a mochila por cima do portãozinho.

A relação família e escola inicia-se na creche quando os bebês deixam o cuidado exclusivo da mãe e passam a vivenciar outras experiências com outras pessoas, em um outro ambiente que não o lar. São duas referências, família e professor, que se relacionam diante de um ponto em comum: a criança. Assim, nas instituições de educação dos pequenos, conhecer cada criança torna-se imprescindível para o sucesso do processo. Porém, só conhecer as crianças não basta quando se busca a educação compartilhada, que prevê a troca, a interação entre pais e professores, o envolvimento entre instituição educacional e familiar. E, para tanto, conhecer as famílias torna-se fundamental.

Cada família possui suas especificidades, seus modos próprios de relacionar-se com o mundo, de entender e de estabelecer contato com as pessoas que fazem parte de seu cotidiano. Como afirma Szymanski (2010), o importante é conhecer o tipo de vida que estão oferecendo ao filho/à filha e não somente identificar o tipo de família.

Conhecer o que as famílias são e como se caracterizam pode nos trazer informações importantes. Como afirma Lahire (1995, p. 72), “[...] o fato de os diferentes membros das famílias contextualizadas agirem como agem, de seus filhos serem o que são e comportarem-se como tal nos espaços escolares não é fruto de causas únicas que agiriam poderosamente sobre eles", as famílias estão envolvidas em um conjunto de fatos que os tornam o que são.

Conjunto de fatos que se estabelecem nas

\footnotetext{
*Endereço eletrônico: leticiacasannova@gmail.com
} 
configurações das famílias e percorrem o grau de escolarização, seu trabalho, a renda familiar, sua relação com os outros membros da família e da comunidade, suas vivências e suas experiências. Nesse sentido, é importante destacarmos que há uma variedade de formas familiares nas sociedades humanas e as relações que estabelecem com sua vida cotidiana e com os significados que atribuem ao mundo são diversos. Saraceno e Naldini (2003, p. 20) complementam nossa ideia registrando que "[...] a experiência familiar, que também parece ser a mais comum no tempo e no espaço, distingue, portanto, de maneira mais ou menos profunda, as várias culturas e grupos, sendo também cada um deles atingido de forma diferente pelas transformações sociais".

Fala-se, então, de pluralidade, de diversidade, de formas diferentes de constituir-se a família. Fala-se de perceber e reconhecer a família como categoria plural nas instituições de Educação Infantil. Dessa forma, fortalece-se o objetivo deste trabalho: discutir a relação entre creche e famílias no contexto da pós-modernidade. Para tanto, utilizou-se da pesquisa bibliográfica, uma modalidade de estudo e análise de documentos de caráter científico (OLIVEIRA, 2007), que remete, neste estudo, para as contribuições de diferentes autores sobre a relação escola e família na contemporaneidade.

$\mathrm{O}$ artigo organiza-se em dois momentos: o primeiro trazendo a relação creche e famílias no contexto da mudança, da mulher no campo de trabalho e do esvaziamento da família nuclear. O segundo momento reflete sobre a relação creche e famílias no contexto da pós-modernidade, retratando a singularidade, a diversidade de cada família que precisa ser conhecida pela creche.

\section{A relação creche e famílias: o contexto da mudança}

A creche faz parte de um contexto histórico que, por muito tempo, significou um lugar para as mães deixarem seus filhos enquanto trabalhavam. Nesse contexto, as ações limitavam-se ao assistencialismo e à pura conduta de cuidado. Observa-se, tanto no campo acadêmico (BONDIOLI; MANTOVANI, 1998; PORTUGAL, 1998; OLIVEIRA, 2002; CERISARA， 2002; DAHLBERG; MOSS; PENCE, 2003; POST; HOHMANN, 2003; GOLDSCHMIED; JACKSON, 2006; FORTUNATI, 2009; BARBOSA; RICHTER, 2009) quanto nas legislações (BRASIL, 1996, 2009) uma premissa: a creche não deve ser um simples lugar somente para as crianças serem deixadas, mas sim um ambiente que favoreça o desenvolvimento integral de cada criança, um lugar para aprender.

As crianças permanecem, em média, cerca de dez horas nas instituições de Educação Infantil e vivenciam situações diversas, em espaços específicos e com uma rotina estabelecida. Nesse ambiente, elas comem, brincam, socializam-se, são cuidadas e educadas. Mas nem sempre foi assim.

A educação das crianças pequenas, segundo Kuhlmann Jr. e Fernandes (2004), foi, por muito tempo, considerada responsabilidade única da família e do grupo social ao qual pertenciam. Era com os adultos e com as demais crianças que se aprendia a tornar-se membro de um grupo, participar das tradições consideradas importantes e apropriarse de conhecimentos que lhes seriam necessários para a vida adulta. Por um bom período da história da humanidade, nenhuma instituição incumbiu-se de compartilhar a responsabilidade pela criança com seus pais e com a comunidade da qual esta fazia parte.

$\mathrm{Na}$ atualidade, essa relação é mantida de maneira diversificada. $\mathrm{O}$ que antes era de extrema responsabilidade da família passou a ser compartilhada com as instituições de Educação Infantil. Como define Rosemberg (1995), os movimentos de liberação da mulher, nos anos de 1960 e de 1970, diminuíram a distância entre papéis masculinos e femininos, incentivaram à participação das mulheres no mercado de trabalho e questionaram o exercício da maternidade como o único destino feminino. Portugal (1998) também ressalta que as atuais condições de nossa sociedade fizeram com que houvesse uma alteração de valores relativos à atuação da mulher e da criança. Para a autora, a emancipação da mulher é um fato que "[...] para além de induzir profundas alterações socioeconômicas na coletividade em geral, do ponto de vista psicológico, expressa modificações profundas na própria maneira de estar, de ser e de querer da mulher nas sociedades actuais" (PORTUGAL, 1998, p. 123).

Na contemporaneidade, observa-se mais um fenômeno de mudança. Os novos arranjos familiares distanciam-se dos padrões familiares considerados típicos da sociedade moderna: a família nuclear. Bruschini (1989) ilustra, por meio dos estudos de Parsons e Bales (1955), as características dessa família nuclear:

Parsons propõe o estudo da família nuclear como um pequeno grupo tarefa, no qual os membros adultos desempenham papéis altamente diferenciados, assimétricos e complementares, o que possibilita a presença de modelos masculinos 
e femininos claramente definidos [...] o adulto masculino ou marido-pai é o líder 'instrumental' do grupo, enquanto o adulto feminino desempenha papéis sociais de natureza 'expressiva', voltados principalmente para os assuntos internos da família (BRUSCHINI, 1989, p. 2).

Observamos esse sentido de família moderna e nuclear distanciando-se da realidade de famílias compostas por pai, mãe e irmãos ou apenas pela mãe, ou somente pelo pai, pela mãe e os avós, pelas uniões monoparentais, pelos filhos convivendo com pais separados e os filhos do segundo casamento. Algumas mudanças, após os anos de 1960, na França, são reconhecidas por Singly (2007) e marcam esse novo contexto da família na sociedade: a diminuição do número de casamentos e o aumento de uniões livres; aumento dos divórcios, das separações; o crescimento das famílias monoparentais, das famílias compostas ou recompostas, no qual um dos cônjuges é separado e casa-se novamente; diminuição do número de nascimentos; aumento do número de nascimentos fora do casamento; aumento do trabalho assalariado das mulheres; cônjuges com atividade profissional.

Houve, assim, uma reorganização das relações entre família e sociedade, e, por consequência, das relações entre as famílias e as instituições complementares como as creches, préescolas e escolas. Saraceno e Naldini (2003, p.23) destacam que "[...] a família possui igualmente uma história interna própria, que transforma continuamente quer as regras e os modos das relações entre os sexos e as gerações, quer as relações e os intercâmbios entre família e sociedade".

Assim, as instituições, bem como o processo de educação das crianças pequenas, também foram se modificando. $\mathrm{O}$ que antes era de extrema responsabilidade da família passou a ser compartilhada com as instituições de Educação Infantil. São duas referências, família e professor que se relacionam diante de um ponto em comum: a criança. É nessa interação que surge um mundo de novidades, de descobertas, de sensações, de sentimentos da família em relação à instituição e vice e versa.

Toda essa condição também tomou forma legal a partir da nova Constituição Brasileira (1988) e em decorrência da Lei de Diretrizes e Bases da Educação Nacional (Lei n9394/96), a qual prevê que a educação oficial pública, do Estado, conta com uma nova modalidade: Educação Infantil - dever do Estado e direito subjetivo da criança desde 0 até 5 anos.

Com essa decisão, estabelece-se, em termos teóricos, uma prioridade que revoluciona a perspectiva educacional no Brasil e traz questões que precisam ser respondidas: Qual seria a especificidade da Educação Infantil? Quais conceitos e concepções estariam presentes nas ações e nas atividades das instituições? Qual o papel do profissional dessa faixa etária? Qual o papel das famílias nesse contexto? Quais interações se estabeleceriam entre creche e famílias?

Observa-se que não é mais possível concebermos a família como uma instituição com características comuns a todas, pois, como afirma Peixoto,

[...] o que observamos não foi exatamente o enfraquecimento da instituição família, mas o surgimento de novos modelos familiares, derivados desses fenômenos sociais e, sobretudo, das transformações nas relações de gênero, que se exprimem através do controle de natalidade, da inserção intensiva da mulher no mercado de trabalho, das mudanças ocorridas na esfera da sexualidade, entre outros fatores [...] o cenário torna-se, assim, cada vez mais complexo (PEIXOTO, 2007, p. 9).

Para Lahire (2006, p. 57), “[...] é impossível agir como se estivéssemos ligados a um espaço cultural homogêneo". Percebe-se que as identidades unificadas, que representavam um estilo, uma classe e que por tanto tempo estabilizaram a sociedade, estão em declínio, fazendo surgir novas identidades.

Esse movimento pode ser percebido por intermédio dos perfis de quatro famílias que moram no mesmo bairro, utilizam-se da mesma creche e dispõem de características diversificadas. Essas famílias participaram da pesquisa intitulada $O$ que as crianças pequenas fazem na creche? As famílias respondem (CASANOVA, 2011) ${ }^{1}$. Seus perfis ilustram a pluralidade e a diversidade de cada família.

A família da Laura, de 1 ano, é composta pela mãe de 22 anos, o pai com 34 anos, os quais moram junto com o avô. Um pouco antes da entrevista permanecemos na cozinha enquanto a mãe terminava o banho da Laura e o avô conversava com ela na banheira. O banho é uma coisa que a mãe não faz questão que as professoras deem na creche porque ela sempre quer fazê-lo quando chega à casa. O pai trabalha como segurança, não estava em casa no momento da entrevista e vai à creche raramente. A mãe é 
funcionária pública e trabalha na Secretaria de Obras como secretária de um departamento. A renda mensal gira em torno de 9 salários mínimos [...] A mãe, que participou da entrevista, é bastante comunicativa e registra suas ideias com clareza. Fez questão de mostrar as lembrancinhas que a Laura fez e que estão penduradas em um quadro na parede da cozinha. A casa possui uma cozinha grande, uma sala e dois quartos. Observamos muitos brinquedos por todos os cômodos da casa. Para ela, para trabalhar com bebês “[...] o principal é gostar de criança, porque quando gosta do que tu fazes, tu não vai medir esforços pra... [pensando]... tu vai estudar, tu vai se especializar. É igual a mim, o meu sonho e do meu marido era ter a Laura, então como era uma coisa que a gente queria, uma coisa que a gente gostava, foi aí que a gente ia atrás, que a gente leu, pesquisou, se aprofundou no assunto" (Mãe de Laura) (CASANOVA, 2011, p. 39-55).

Afamília da Ana, de 1 ano e 5 meses, é composta pela mãe e a avó, que moram na mesma casa. A mãe, de 21 anos, foi quem participou da entrevista e respondeu sempre de forma convicta às perguntas. Ela possui o ensino médio completo, trabalha como auxiliar de escritório, recebe mensalmente dois salários mínimos e meio, incluindo a pensão alimentícia. A mãe conta que nunca foi casada com o pai da Ana e que essa situação a incomodava no início, pois o pai já estava em um outro relacionamento. Contudo, repensou algumas coisas e percebeu que a filha precisava do pai. Hoje, Ana passa os finais de semana com a família do pai e todos conversam frequentemente. [...]. Na creche, ela conta que a filha já fez amizades e relata que começou a observar, depois de uma conversa com a mãe da Laura, que a filha quando chega vai direto ao berço em que a Laura está. É a avó que leva Ana à creche pela manhã e ela vai buscá-la no final da tarde. Quando perguntada sobre o que ela achava que a filha ficava fazendo o dia inteiro na creche, ela respondeu: "Eu acredito que ela fique fazendo bastante atividade educativa, porque a Ana de uns dias pra cá eu reparei que tu pergunta pra ela assim: 'Ana cadê teu olho?' Que antes ela só sabia onde era a barriga. E agora tu pergunta: 'onde é o olho?' Ela já te mostra. 'Onde que é o nariz?' Ela já bota a mão. 'A boca?'. Eu acredito que seja mais ou menos isso" (Mãe da Ana) (CASANOVA, 2011, p. 3866).

Assim, como no caso da família do Pedro, de 2 anos e 3 meses, que mora nos fundos do terreno da casa de parentes. Uma residência pequena que dispõe de um quarto, cozinha e uma sala. Moram a mãe, o Pedro, um irmão de 8 anos e uma irmã com 9 anos. O pai está preso e a família sobrevive com um salário mínimo do trabalho de doméstica da mãe, de 27 anos e que estudou até o ensino fundamental. Os irmãos são os responsáveis por levar e buscar o Pedro da creche, mas, pelo menos uma vez por semana, a mãe gosta de ir para conversar com as professoras. [...]. Enquanto a entrevista acontecia na cozinha, Pedro estava completamente à vontade brincando no quintal, e a mãe pedia que a irmã cuidasse dele, pois ele já estava mexendo na água e no cachorro. Para a mãe: "Não tenho nem palavras pra dizer que a creche me ajuda bastante, se não fosse a creche eu não sei, porque trabalhar pra pagar alguém pra cuidar deles não compensa. Imagina trabalhar de doméstica, ganhar um salário $e$ pagar pra cuidar das outras crianças enquanto eu saio de dentro de casa" (CASANOVA, 2011, p. 42-45).

A família do José e da Maria, 10 meses e 2 anos e 7 meses, respectivamente, dispõe de dois salários mínimos para as despesas mensais da mãe, de 24 anos, da irmã, de 5 anos - que também frequenta o centro de educação infantil no período matutino -, e do José e da Maria. O pai faleceu há mais ou menos sete meses. Desde então, a mãe, que só estudou até a quarta série do ensino fundamental, começou a trabalhar com a confecção de bolsas em casa para aumentar a renda e precisou colocar as crianças na creche. A entrevista foi marcada no final de semana pela manhã e, quando a pesquisadora chegou à casa da família, a mãe relatou que tinha acabado de acordar, pois, como o José estava doente, ela tinha ido dormir muito tarde. O José e a irmã mais velha ainda dormiam no único quarto e a entrevista aconteceu na cozinha. A casa dispõe desses dois cômodos e fica aos fundos da residência de parentes. A mãe contou que "[...] dava mamadeira pra ele antes de ir e a professora falou que não precisa dar porque chega lá ganha mamadeira todo mundo, aí ele come. Mas como ele chora de manhã, eu dou sem elas saberem mesmo" (Mãe de José e Maria) (CASANOVA, 2011, p. 41-74).

Podemos dizer que as instituições de Educação Infantil interagem apenas com um tipo de família? Que os momentos de interação são percebidos da mesma forma por cada família? Que as relações devem se estabelecer do mesmo jeito com todas as famílias?

Esse é um movimento de transformações, de perceber que, em uma sala de crianças pequenas, 
assim como há uma criança diferente da outra, há também uma família diferente da outra. Para autores como Hall (2014) e Lyotard (2013), esse movimento denomina-se pós-modernidade, no qual há uma ruptura com os pensamentos da modernidade.

Assim, para Hall (2014, p. 10, grifo do autor), o sujeito da modernidade era aquele sujeito totalmente "[...] centrado, unificado, dotado de capacidades de razão, de consciência de ação, cujo 'centro' consistia num núcleo interior'. Já o sujeito pós-moderno não tem uma identidade fixa, essencial ou permanente, "[...] a identidade torna-se uma 'celebração móvel': formada e transformada continuamente em relação às formas pelas quais somos representados ou interpelados nos sistemas culturais que nos rodeiam" (HALL, 2014, p. 10, grifo do autor),

Dessa forma, é necessário compreendermos a relação creche e famílias nesse contexto pósmoderno, de mudanças, de heterogeneidades, de pluralismo cultural, de verdades provisórias e de complexidades. Descarta-se, assim, a ideia de que a creche atua exclusivamente com um tipo de família e fortalece-se o conceito de que a creche está constantemente relacionando-se com as famílias no plural.

\section{A relação creche e famílias: o contexto da pós- modernidade}

Partimos do pressuposto de que as famílias possuem diversas fontes de influência, no sentido de tornarem-se pais e mães, de educarem seus filhos, de aprenderem a lidar com as crianças. Os demais membros das famílias como avós, tios, primos, bem como o seu ambiente de trabalho, suas leituras, suas conversas com vizinhos acabam influenciando as atitudes dessa mãe e desse pai. A creche, o espaço educativo institucionalizado, também é uma fonte de influência para as famílias e deveria ser um espaço em que todos os envolvidos, crianças, profissionais e famílias, estivessem em constante interação. Para tanto, é necessário que se fortaleçam mecanismos conscientes e consistentes de interação, de forma que a própria instituição mostre o que produz, fale sobre o que faz, evidencie o desenvolvimento de cada criança, conduza os pais e as crianças em um processo de aprender. Dessa maneira, a creche superará o conceito de ser um simples lugar para deixar as crianças enquanto a família trabalha.

Nas instituições de educação dos pequenos, conhecer cada criança torna-se imprescindível para o sucesso do processo de desenvolvimento e para a prática pedagógica. Contudo, só conhecer as crianças não basta. Na educação compartilhada, a interação entre pais e professores, o envolvimento entre instituição educacional e familiar é fundamental. Assim, conhecer as famílias torna-se essencial, pois cada uma possui suas especificidades, com modos próprios de relacionar-se com o mundo, de entender e estabelecer contato com as pessoas que fazem parte do seu cotidiano.

Pensar a relação entre creche e famílias é considerar o nível de compartilhamento existente entre essas duas instituições responsáveis pela educação dessas crianças. Para Fortunati:

A ideia de que os serviços educacionais para a primeira infância tenham como interlocutores não só as crianças, mas também os pais, procede de uma ideia sobre o desenvolvimento com empresa conjunta entre as crianças e as pessoas que as atendem e põe em evidencia a importância de que existe uma troca contínua e recíproca entre os diferentes contextos em que as crianças crescem (FORTUNATI, 2009, p. 52).

Portugal (1998) alerta-nos para a necessidade de observação do impacto da creche para e nos pais, pois considera que a creche faz parte de um sistema mais global de apoio às famílias. Por isso, conhecer o que as famílias são e como elas se caracterizam pode nos trazer informações importantes. Como afirma Lahire (1995, p. 72), “[...] o fato de os diferentes membros das famílias contextualizadas agirem como agem, de seus filhos serem o que são e comportarem-se como tal nos espaços escolares não é fruto de causas únicas que agiriam poderosamente sobre eles" - as famílias estão envolvidas em um conjunto de fatos que os tornam o que são.

Conjunto de fatos que se estabelecem nas configurações das famílias e percorrem o grau de escolarização, seu trabalho, a renda familiar, sua relação com os outros membros da família e da comunidade, suas vivências e experiências. Dessa forma, podemos afirmar que a creche não se relaciona com um único tipo de família: a família relapsa ou a família interessada, a família pobre ou a família rica, a família boa ou a família ruim. A creche se relaciona com uma multiplicidade de famílias, cada uma com suas configurações, suas vivências, seus conhecimentos, suas experiências culturais.

Essa relação com a multiplicidade, com a família formada por indivíduos que estão imersos em diferentes e inúmeras representações culturais, é caracterizada pelo contexto da pós-modernidade. 
Como afirma Hall:

A identidade plenamente unificada, completa, segura e coerente é uma fantasia. Ao invés disso, à medida que os sistemas de significação e representação cultural se multiplicam, somos confrontados por uma multiplicidade desconcertante e cambiante de identidades possíveis [...] (HALL, 2014, p. 12).

As famílias são vistas menos como instituição e mais como espaço de socialização, no qual "[...] o indivíduo não se define mais pelos laços familiares (filho de sicrano ou mulher de fulano)" (SINGLY, 2007, p. 16), marca da modernidade. Na pós-modernidade, como exemplifica Singly (2007), os indivíduos da família têm pertencimentos múltiplos. $\mathrm{O}$ autor reforça que, na modernidade, o elo social seria composto por fios mais sólidos como o pertencimento à determinada nação, classe social, raça e gênero. Em contrapartida, na contemporaneidade, os elos seriam menos sólidos, mas teriam muitos mais fios do que tinham antes.

Dessa forma, as famílias não podem mais ser caracterizadas, por exemplo, apenas pela sua condição socioeconômica, de famílias pobres ou ricas. Para Lahire (2006, p. 403), os elos da contemporaneidade são caracterizados pelas vivências em condições materiais e culturais de existências diferentes, pelas "[...] mobilidades sociais, escolares ou profissionais, pequenas ou grandes, que imprimem suas marcas nos perfis culturais".

Percebe-se que a família não desaparece na pós-modernidade, mas ela muda de sentido. Ela tem como característica a abertura de um maior espaço para o indivíduo e suas interações sociais. Assim, é necessário interpretarmos as famílias como um conjunto de atores. Para Lahire (2002, p. 198), “[...] os atores são o que as suas múltiplas experiências sociais fazem deles. São chamados a ter comportamentos, atitudes variadas segundo os contextos em que são levados a evoluir".

A consciência de qualquer ser social só se forma e adquire existência por meio das múltiplas relações que ele estabelece, no mundo, com o outro (LAHIRE, 1995). A creche, como contexto social dessas famílias, também é fonte de construção dos esquemas de ação, no qual as famílias aprendem modos de agir, de apreciar, de orientar e de relacionar-se. Diante das relações estabelecidas entre creche e família, do que os pais estão se apropriando? O que as famílias estão aprendendo? Como a creche vê as famílias?
Ao refletir sobre a última questão, observase que os profissionais da educação juntam, em uma mesma categoria, realidades consideradas diferentes. É comum o discurso de que a família não participa e não se interessa pela vida escolar de seus filhos. Segundo Lopes e Guimarães (2008), para os profissionais da Educação Infantil, constrói-se uma imagem de uma família que vê a instituição como um "depósito de crianças". Contudo, será que todas as famílias veem da mesma forma e agem do mesmo jeito? Será que conseguiríamos identificar formas diferenciadas de participação?

Como afirma Lahire (1995, p. 12, grifo do autor), "[...] quando os professores falam de uma forma muito genérica, as 'grandes causas sociais' tornam-se predominantes" - como as afirmações que os pais não conversam mais com os filhos ou que eles não têm mais tempo ou vontade. Dessa forma, a homogeneidade do ambiente familiar é fortalecida no ambiente escolar, assim como as ações generalistas de interação com essas famílias.

Observam-se, na prática educativa da creche, ações universalistas de relação com as famílias que definem uma mesma ação para todas as famílias. No entanto, se é percebido que a creche se relaciona com famílias na sua pluralidade, como é possível assegurar um discurso totalizante, generalista e que pretende dar respostas e soluções a todo contingente, que é múltiplo e complexo? Para tanto, seria necessário que a creche reconhecesse o contexto das famílias na sua pluralidade e garantisse ações que valorizassem as disposições e as variações individuais de cada família (LAHIRE, 2004).

Essa prática de entender as famílias de forma generalizada transforma a relação dessas famílias com a creche em uma relação superficial, configurada pelas conversas rápidas e pouco significativas. Fortunati (2009, p. 53, grifo do autor) ressalta que essas "[...] formas de encontro entre família e o serviço se apresenta mais como 'rituais' vazios que como o curso de um processo de relação dinâmico".

Para uma relação dinâmica, a creche precisa reconhecer a pluralidade das famílias e não condicionar as interações com os pais a formatos universais. É necessário compreender que, no contexto da pós-modernidade, não cabe mais entender as famílias e planejar ações para elas como se elas ainda representassem a família nuclear da modernidade.

\section{Considerações}


No ambiente da creche, as relações entre as famílias e a instituição dão-se praticamente em dois momentos bem específicos: na entrada e na saída das crianças; e; esporadicamente; nas reuniões de pais. As mães, os pais, os irmãos mais velhos, os avôs e as avós interagem de forma diversificada, de acordo com a disponibilidade de tempo de cada um.

Os momentos de interação entre creche e famílias são marcados pela complexidade do contexto pós-moderno. As famílias são configuradas em sua multiplicidade, por indivíduos que vivenciam experiências socializadoras diversas. Porém, para a creche, a visão da família moderna e nuclear continua marcada nos discursos generalistas de que a família não participa, não tem conhecimento e nem interesse.

Encontra-se, aqui, a dualidade na relação creche e famílias. Por um lado, as famílias são caracterizadas no contexto da pós-modernidade como não tendo uma identidade fixa, transformando-se continuamente à medida que interagem com os sistemas culturais que as rodeiam. Por outro lado, a creche entende as famílias de forma generalista, como uma instituição em que todos os indivíduos agem da mesma maneira. Pode-se dizer que a creche planeja ações de interação com um tipo de família e descartase a ideia de que a creche está constantemente relacionando-se com as famílias no plural.

Dessa forma, observa-se, na prática educativa da creche, ações generalistas de relação com as famílias que definem uma ação única para todas elas. Porém, no contexto da pós-modernidade, no qual a instituição de Educação Infantil relacionase com famílias na sua pluralidade, torna-se inviável assegurar um discurso totalizante e que pretende dar respostas e soluções a todo contingente de famílias, pois estas são traduzidas como múltiplas e complexas.

\section{Nota}

1 Os exemplos citados fazem parte da pesquisa de Mestrado em Educação desenvolvida pela autora e foi submetida ao processo de autorização solicitado pelo Conselho de Ética para divulgação das entrevistas.

\section{Referências}

BARBOSA, Maria Carmen Silveira; RICHTER, Sandra Regina Simonis. Os bebês interrogam o currículo: as múltiplas linguagens na creche. In:
CONGRESSO DE LEITURA DO BRASIL, COLE, 17., 2009, Campinas. Anais... Campinas, SP: UNICAMP, 2009.

BONDIOLI, Anna; MANTOVANI, Susanna. Manual de educação infantil: de 0 a 3 anos. Porto Alegre: Artmed, 1998.

BRASIL. Resolução CEB 5/2009, de 17 de dezembro de 2009. Fixa as Diretrizes Curriculares Nacionais para a Educação Infantil. Diário Oficial [da] República Federativa do Brasil, Brasília, DF, 18 dez. 2009. Seção 1, p. 18.

Lei $n^{\circ}$ 9.394, de 20 de dezembro de 1996. Estabelece as Diretrizes e Bases da Educação Nacional. Diário Oficial [da] República Federativa do Brasil, Brasília, DF, v. 134, n. 248, 23 dez. 1996. Seção 1, p. 27834-27841.

BRUSCHINI, Cristina. Uma abordagem sociológica de família. Revista Brasileira de Estudos de População, São Paulo, v. 6, n. 1, p. 1-23, jan./jun. 1989.

CASANOVA, Letícia. $O$ que as crianças pequenas fazem na creche? As famílias respondem. 2011. 114 f. Dissertação (Mestrado em Educação) Universidade do Vale do Itajaí, Itajaí, 2011.

CERISARA, Ana Beatriz. Referencial Curricular nacional para educação infantil no contexto das reformas. Educação \& Sociedade, Campinas, v. 23, n. 80, p. 329-348, 2002.

DAHLBERG, Gunilla; MOSS, Peter; PENCE, Alan. Qualidade na educação da primeira infância: perspectivas pós-modernas. Porto Alegre: Artmed, 2003.

FORTUNATI, Aldo. A educação infantil como projeto da comunidade. Crianças, educadores e pais nos novos serviços para a infância e a família. Porto Alegre: Artmed, 2009.

GOLDSCHMIED, Elinor; JACKSON, Sonia. Educação de 0 a 3 anos: o atendimento em creche. 2. ed. Porto Alegre: Artmed, 2006.

HALL, Stuart. A identidade cultural na pósmodernidade. Tradução Tomaz Tadeu da Silva \& Guacira Lopes Louro. Rio de Janeiro: Lamparina, 2014. 
KUHLMANN JR., Moysés; FERNANDES, Rogério. Sentidos da infância. In: FARIA FILHO, Luciano Mendes de. (Org.). A Infância e sua Educação. Belo Horizonte: Autêntica, 2004, p. 2237.

LAHIRE, Bernard. A cultura dos indivíduos. Porto Alegre: Artmed, 2006.

Homem plural: os determinantes da ação. Petrópolis: Vozes, 2002.

Sucesso escolar nos meios populares: as razões do improvável. São Paulo: Ática, 1995.

LYOTARD, Jean-François. A condição pósmoderna. Tradução Ricardo Corrêa Barbosa. Rio de Janeiro: José Olympio, 2013.

OLIVEIRA, Maria Marly. Como fazer pesquisa qualitativa. Petrópolis, Vozes, 2007.

OLIVEIRA, Zilma Ramos de. Educação Infantil: fundamentos e métodos. São Paulo: Cortez, 2002.

PARSONS, Talcott; BALES, Robert Freed. Family, socialization and interaction process. Glencoc: Free
Press, 1995

PORTUGAL, Gabriela. Crianças, famílias e creche - uma abordagem ecológica da adaptação do bebé à creche. Porto: Porto, 1998.

POST, Jacalyn; HOHMANN, Mary. Educação de bebés em infantários - cuidados e primeiras aprendizagens. Lisboa: Fundação Calouste Gulbenkian, 2003.

ROSEMBERG, Fúlvia. A criação de filhos pequenos: tendências e ambiguidades contemporâneas. In: RIBEIRO, Ivete; RIBEIRO, Ana Clara. (Orgs.). Família em processos contemporâneos: inovações culturais na sociedade brasileira. São Paulo, Loyola, 1995, p.167-190.

SARACENO, Chiara; NALDINI, Manuela. Sociologia da família. Lisboa: Estampa, 2003.

SINGLY, François de. Sociologia da Família Contemporânea. Rio de Janeiro: FGV, 2007.

SZYMANSKI, Heloisa. A relação família/escola: desafios e perspectivas. Brasília: Liber Livro, 2010.

\section{Sobre a autora}

Letícia Veiga Casanova: Professora da educação infantil no município de Itajaí (SC) e Mestre em Educação pela Universidade do Vale do Itajaí - UNIVALI. Membro do Grupo de Pesquisa Contextos da Educação da Criança, como doutoranda em Educação pela mesma instituição.

Recebido em janeiro de 2016.

Aprovado em março de 2016. 